\title{
Perceived Barriers in Accessing Health Care and the Risk of Pregnancy Complications in Indonesia
}

\section{Anissa Rizkianti $\mathbb{D}$ \\ Ika Saptarini \\ Rika Rachmalina}

Center for Research and Development of Public Health Efforts, National Institute of Health Research and Development, Ministry of Health, Jakarta, Indonesia
Correspondence: Anissa Rizkianti Jalan Percetakan Negara No. 29, Jakarta, Indonesia

Tel +62 2l 42832972

Email anissa.rizkianti@kemkes.go.id
Background: Accessing immediate health care during pregnancy is key to preventing and treating pregnancy-related complications, which are the leading cause of maternal morbidity and mortality. As the largest archipelago country in the world, Indonesia faces the challenges of disparity in access to healthcare services across geographical regions and socioeconomic groups.

Objective: This study aims to assess the relationship between perceived barriers to accessing health care and the risk of pregnancy-related complications among women of reproductive age in Indonesia.

Methods: Data from a nationally representative sample of 15,021 last births within 5 years preceding the 2017 Indonesia Demographic and Health Survey were analyzed to examine barriers in accessing health care and the risk of having complications during pregnancy. The statistical model of logistic regression was used to investigate the effect of barriers on the risk of pregnancy complications, and results were presented as odds ratios (ORs) with 95\% confidence intervals (CIs).

Results: The majority of women in Sumatra and Maluku-Papua regions encountered physical, cultural, and financial barriers to accessing health care. The results indicate significantly higher odds of having complications in mothers who had distance barriers (OR: 1.46, 95\% CI: 1.20-1.77), relative to mothers who reported no barriers, after adjusting for women's characteristics.

Conclusion: The findings suggest that it is necessary to tackle specific physical barriers by providing more developed health-care systems in rural and geographically isolated areas, to bring health services closer to home.

Keywords: barriers, access to health care, complication, Indonesia

\section{Introduction}

Complications in pregnancy, during childbirth, and after delivery are the most common causes of maternal deaths in Indonesia, and could be avoided in the majority of cases. These complications include severe bleeding (30.3\%), pregnancy-related hypertension (27.1\%), and infections (7.3\%). ${ }^{1}$ Addressing maternal complications has been placed as a priority among the strategies to reduce maternal mortality.

Globally, it is estimated that $15 \%$ of pregnant women develop a potentially lifethreatening complication. ${ }^{2}$ Maternal complications can not only affect the mother's and newborn's health, but also have social and economic consequences for the family. ${ }^{3}$ Previous studies in Indonesia have examined several risk factors for maternal complications, including nullipara, younger and older age, low socioeconomic status, urban residence, and poor-quality antenatal visits. ${ }^{4-6}$ 
As home to over 260 million people who are broadly dispersed across 34 provinces, Indonesia faces disparities in healthcare utilization. The utilization of healthcare services is mainly related to the accessibility of services. For instance, geographical and financial barriers, such as antenatal care (ANC) and delivery services, have long been documented as major challenges to the distribution of maternal healthcare access. ${ }^{7-9}$ Moreover, studies have established that these barriers lead to delays in access, which could increase the risk of potentially lifethreatening maternal conditions during pregnancy. ${ }^{10}$

The Indonesian health system emphasizes the reduction of inequalities in the management and provision of public health services. However, decentralization has affected the capacity of the central government to maintain integration and alignment across the different levels of the health system, such as the provincial level and district/municipality level. Within the decentralized health system, provincial and district/municipality governments have their own authority and capacity in regulatory processes and coordination of crossdistrict health issues at the provincial and district/municipality levels. ${ }^{11}$ Accordingly, a number of reforms to different aspects of the health system have been introduced, including the introduction of universal health coverage (UHC) in 2014 under the national health insurance program or Jaminan Kesehatan Nasional (JKN). ${ }^{12}$

The JKN program is a national strategy to ensure financial protection in accessing equitable and quality healthcare services. The JKN program was created by combining various health insurance schemes, administered by the Badan Penyelenggara Jaminan Kesehatan (BPJS) Kesehatan (Healthcare and Social Security Agency). ${ }^{12}$ It plays an important role in reducing the financial burden of maternal and child health care, in which ANC services, delivery services, and postpartum care services are integrated into one benefit package within JKN. ${ }^{13}$ However, a large number of women still have poor access to healthcare services and incur out-of-pocket expenditure for delivery care. Also, there are delays in access to care, referrals, and transfers, as well as varying conditions and quality of the facilities, resulting in geographical disparities between Indonesian regions. ${ }^{14}$

Therefore, it is important to prevent pregnancy complications by eliminating the barriers to accessing health care, which need to be promptly recognized and resolved. To address these problems, this study aims to examine the contribution of the barriers to accessing health care to pregnancy complications in Indonesia.

\section{Methods \\ Data and Study Design}

Cross-sectional data from the 2017 Indonesia Demographic and Health Survey (IDHS) were used in this study. The survey collects information on various demographic and health indicators at the national and sub-national levels from a nationally representative sample of 49,261 households across the country. The sample for the survey was selected using a stratified two-stage cluster design consisting of 1970 clusters. Clusters are selected from each stratum using probability proportional to size sampling, meaning that clusters with larger populations are more likely to be selected than those with smaller populations. ${ }^{15}$ Data were collected using structured interviews from 49,627 women aged 15-49 years. Out of the total women included in the survey, 15,021 last live births within the 5 years preceding the survey were reported.

\section{Study Variables}

The outcome variable was the pregnancy complication, defined as having one or more of the following events during the most recent pregnancy: excessive vaginal bleeding, persistent vomiting, convulsion, premature labor, and/or other morbidities. In terms of exposure, the main explanatory variables were barriers related to accessing health care, generated by asking women whether they had serious problems in accessing health care for themselves when they were sick. The types of problem were classified as: 1) problem in getting permission to access health care, 2) problem in not wanting to go alone, 3) problem in getting money needed for treatment, and 4) problem in distance to healthcare facility. Women who said "yes" to each question were considered to experience problems or difficulties preventing them from obtaining health care or treatment.

Other independent variables of interest that could influence pregnancy complications, as established in the previous literature, are examined in this study. These independent variables included respondents' age (categorized as 15-19, 20-34, and 35-49 years); marital status (grouped as never married, married, and widowed/ divorced); parity (categorized as 3 or more, 2, and 1); iron supplementation (defined as taking iron supplements during pregnancy for at least 90 days, and categorized as no and yes); educational level (grouped as no education/ primary, secondary, and higher); wealth index (categorized as poorest, poorer, middle, richer, and richest); working status (categorized as not working and working); and place of residence (categorized as rural and urban). 


\section{Statistical Analysis}

Three levels of analysis were employed in this study. At the univariate level, the percentage distribution of the study sample was presented to show the distribution of respondents by the characteristics stated above. Maps were also drawn to present the distribution of barriers at the provincial level. At the bivariate level, Pearson's chi-squared test was performed to examine the statistically significant relationships between independent variables and pregnancy complications. Multiple logistic regression was applied to further examine the relationships between barriers to accessing health care and the occurrence of pregnancy complications, while adjusting for the effect of other independent variables. The results were presented as estimated adjusted odds ratios (ORs) with $95 \%$ confidence interval (CI). The data analyses were carried out using Stata SE Release $15 .{ }^{16}$

\section{Ethical Considerations}

The 2017 IDHS was granted ethical clearance by the Institutional Review Board of Inner-City Fund (ICF) International and ORC Macro (ICF IRB192 FWA00000845). Prior to the interview, all respondents to the 2017 IDHS were given information about the survey and agreed to participate by submitting written informed consent. Meanwhile, the authors obtained approval to use the 2017 IDHS dataset from the DHS program.

\section{Results}

\section{Characteristics of the Study Sample}

Selected characteristics of the study respondents are presented in Table 1. As displayed in Table 1,23\% of women had no companion during their healthcare visit. More than $15 \%$ reported financial issues as a barrier to accessing health care. Also, $11 \%$ of women had geographical or physical problems, and only $5 \%$ did not receive permission from their husband and reported this as a barrier to accessing health care.

About half of the women (55.8\%) were in the age range of 35-49 years, and the majority (97\%) were married. More than half of the women $(53.5 \%)$ reported having had two or three births and having completed the secondary level of education (58.3\%). Less than half of the total sample were unemployed (45.6\%) and lived in urban areas (48.5\%). In addition to descriptive statistics, visualization is used to describe the disparity of barriers to accessing health care across provinces in Indonesia. The percentage of women who reported the problem of having
Table I Distribution of Pregnancy Complications by Background Characteristics, IDHS 2017

\begin{tabular}{|c|c|c|c|c|}
\hline \multirow[t]{2}{*}{$\begin{array}{l}\text { Background } \\
\text { Characteristics }\end{array}$} & \multirow[t]{2}{*}{$\mathbf{n}$} & \multicolumn{2}{|c|}{$\begin{array}{c}\text { Pregnancy } \\
\text { Complications }\end{array}$} & \multirow[t]{2}{*}{$p$-Value } \\
\hline & & No & Yes & \\
\hline \multicolumn{5}{|l|}{$\begin{array}{l}\text { Problems in getting } \\
\text { permission }\end{array}$} \\
\hline No & 14,118 & 82.7 & 17.3 & 0.13 \\
\hline Yes & 811 & 80.6 & 19.4 & \\
\hline \multicolumn{5}{|l|}{ Problems in getting money } \\
\hline No & 12,630 & 82.8 & 17.2 & 0.11 \\
\hline Yes & 2299 & 81.5 & 18.5 & \\
\hline \multicolumn{5}{|l|}{$\begin{array}{l}\text { Problems in distance to } \\
\text { health care }\end{array}$} \\
\hline No & 13,220 & 83.0 & 17.0 & 0.00 \\
\hline Yes & 1708 & 79.6 & 20.4 & \\
\hline \multicolumn{5}{|l|}{ Problems in going alone } \\
\hline No & 11,693 & 82.8 & 17.2 & 0.39 \\
\hline Yes & 3236 & 82.1 & 17.9 & \\
\hline \multicolumn{5}{|l|}{ Mother's age (years) } \\
\hline $15-19$ & 390 & 86.9 & 13.1 & 0.05 \\
\hline $20-34$ & 6112 & 82.8 & 17.2 & \\
\hline $35-49$ & 8436 & 82.3 & 17.7 & \\
\hline \multicolumn{5}{|l|}{ Marital status } \\
\hline Never married & 23 & 91.3 & 8.7 & 0.54 \\
\hline Married & 14,465 & 82.6 & 17.4 & \\
\hline Widowed/divorced & 450 & 82.9 & 17.1 & \\
\hline \multicolumn{5}{|l|}{ Parity } \\
\hline $4+$ & 2451 & 83.2 & 16.8 & 0.08 \\
\hline $2-3$ & 7826 & 83.1 & 16.9 & \\
\hline 1 & 4661 & 81.6 & 18.4 & \\
\hline \multicolumn{5}{|l|}{ Iron supplementation } \\
\hline No & 8249 & 83.1 & 16.9 & 0.08 \\
\hline Yes & 6689 & 82.0 & 18.0 & \\
\hline \multicolumn{5}{|l|}{ Educational level } \\
\hline Primary & 3848 & 85.3 & 14.7 & 0.00 \\
\hline Secondary & 8458 & 82.2 & 17.9 & \\
\hline Higher & 2632 & 80.3 & 19.7 & \\
\hline \multicolumn{5}{|l|}{ Wealth index } \\
\hline Poorest & 3799 & 85.2 & 14.8 & 0.00 \\
\hline Poorer & 2972 & 84.2 & 15.9 & \\
\hline Middle & 2848 & 82.5 & 17.5 & \\
\hline Richer & 2739 & 79.7 & 20.3 & \\
\hline Richest & 2580 & 80.2 & 19.8 & \\
\hline \multicolumn{5}{|l|}{ Working status } \\
\hline Not working & 7848 & 83.2 & 16.8 & 0.04 \\
\hline Working & 7090 & 81.9 & 18.1 & \\
\hline
\end{tabular}

(Continued) 
Table I (Continued).

\begin{tabular}{|l|r|r|r|r|}
\hline Background & $\mathbf{n}$ & \multicolumn{2}{|c|}{$\begin{array}{c}\text { Pregnancy } \\
\text { Complications }\end{array}$} & \multirow{2}{*}{-Value } \\
\cline { 3 - 4 } & & No & Yes & \\
\hline Place of residence & 7496 & 84.4 & 15.6 & 0.00 \\
Rural & 7442 & 80.8 & 19.2 & \\
Urban & & & & \\
\hline
\end{tabular}

no companion was higher for those living in the Sumatra region, as can be seen from Figure 1. The maps in Figures 2-4 suggest that more women in the provinces of Sumatra and Maluku-Papua region experienced physical, cultural, and financial barriers to accessing health care.

\section{Relationship Between Pregnancy Complications and Perceived Barriers and Other Independent Variables}

Table 1 also presents the percentage distribution of women by the occurrence of pregnancy complications and according to selected characteristics. As presented in Table 1, the percentage of women experiencing at least one complication during pregnancy was significantly higher for women who had distance barriers to accessing health care $(17 \%, p<0.001)$. The occurrence of pregnancy complications was also associated with other selected characteristics analyzed in this study $(p<0.001)$. For instance, the highest percentages of pregnancy complications were encountered among women with higher educational level (19.7\%), women from richer households (20.3\%), and women living in urban areas (19.2\%).

Findings from the multivariate analysis are presented in Table 2. Model 1 presents the unadjusted odds ratios for the independent effects of each of the barrier variables on pregnancy complications. Only the barrier of distance showed a significant association with complications during pregnancy (OR: 1.27, 95\% CI: 1.08-1.49). After adjusting for selected characteristics in Models $2-5$, it can be seen that physical barriers were again the most important predictor of the occurrence of pregnancy complications. As shown in Model 4, the risk of pregnancy complications was almost 1.5 higher for women who reported having problems with the distance to the health facility (OR: $1.43,95 \%$ CI: $1.22-1.69$ ) compared to women who reported no physical barriers. Nevertheless, the relationship between pregnancy complications and other barriers became insignificant after adjusting for women's characteristics.

Model 6 (the final model) examines the influence of all types of barriers to healthcare and other covariates on pregnancy complications. The results indicate a significant relationship between complications during pregnancy and

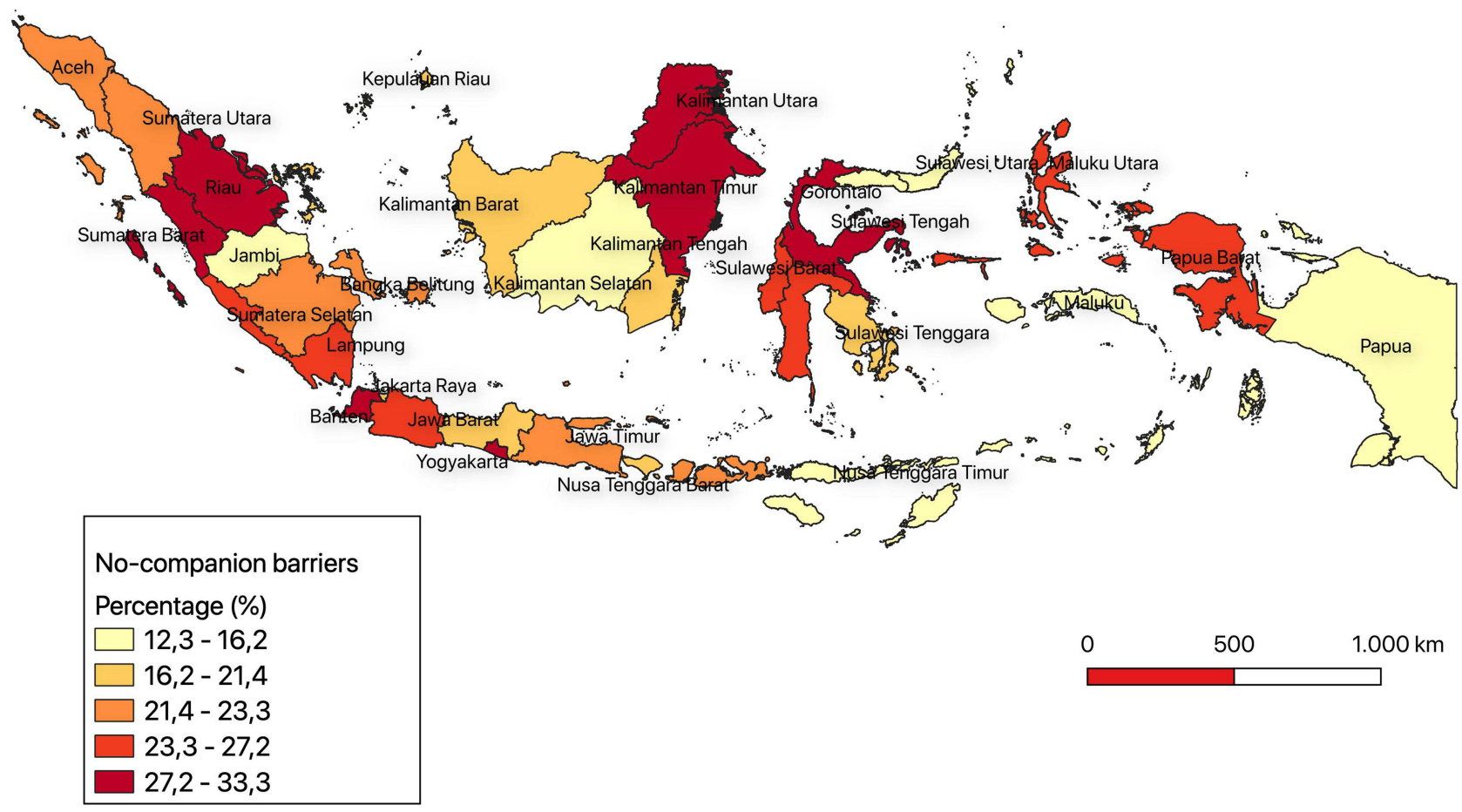

Figure I Distribution of no-companion barriers by province, IDHS 2017. 


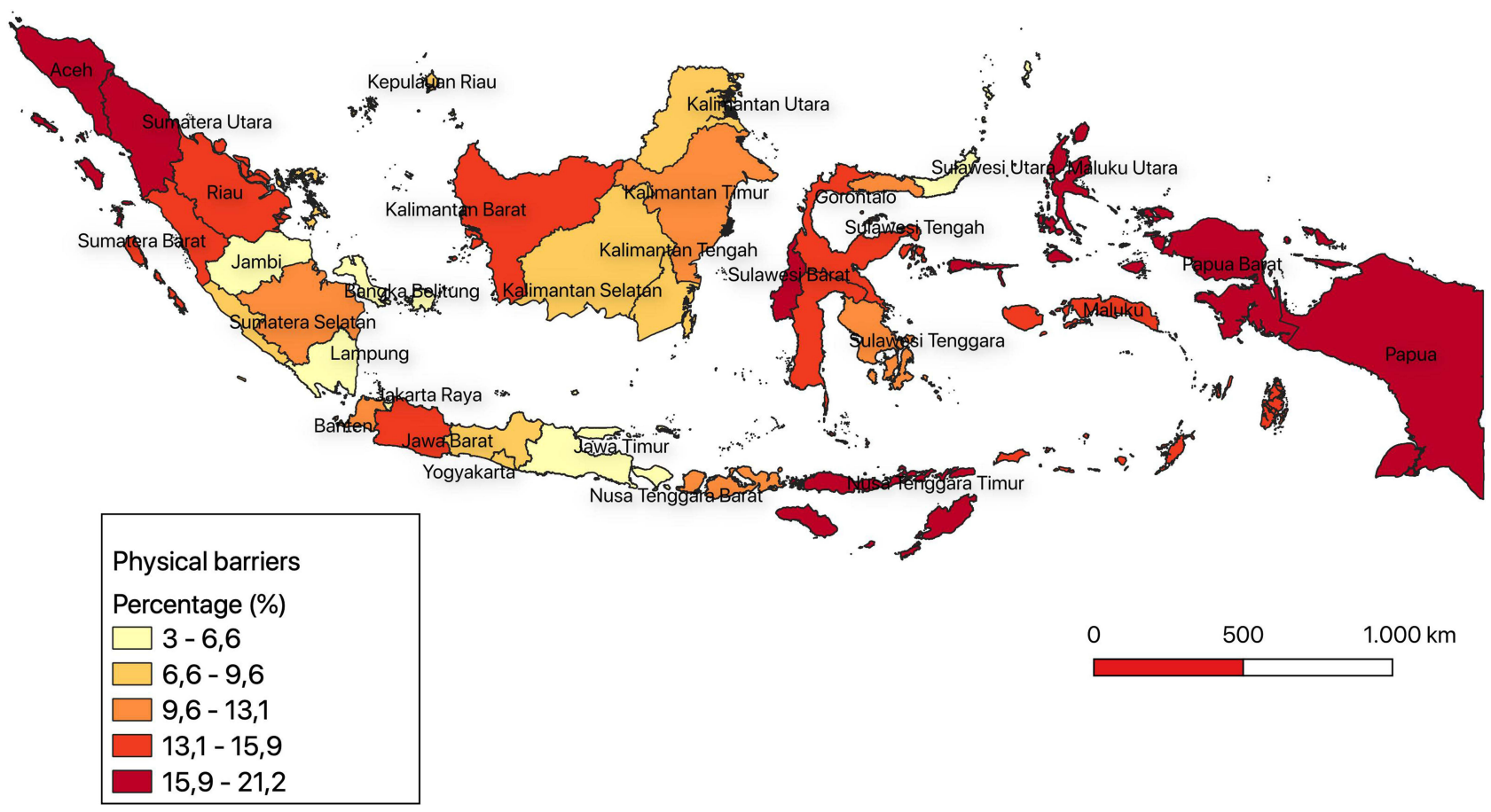

Figure 2 Distribution of physical barriers by province, IDHS 2017.

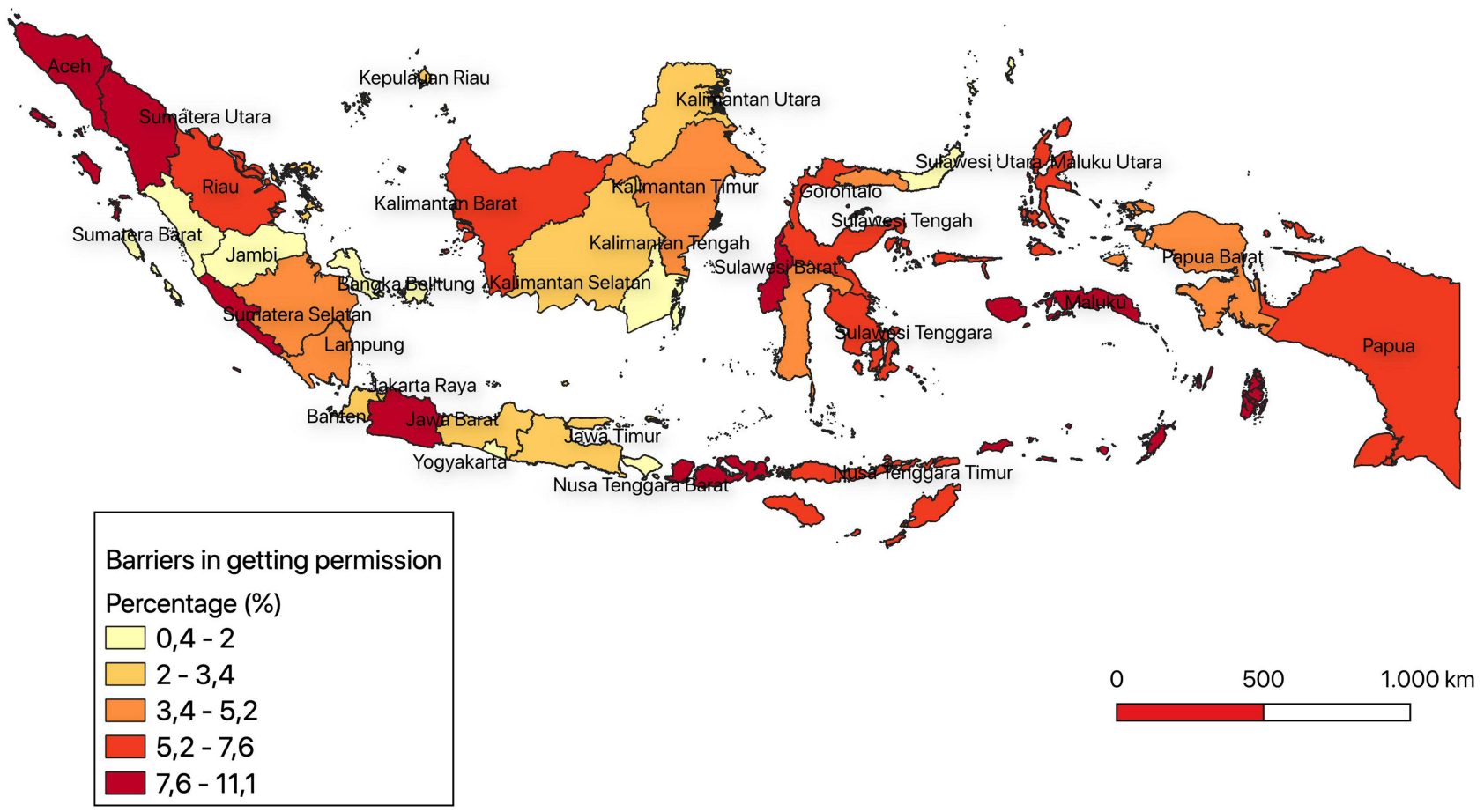

Figure 3 Distribution of barriers in getting permission by province, IDHS 2017.

distance barriers (OR: 1.46, 95\% CI: 1.20-1.77). Other barriers, including obtaining permission, getting money, and having no companion, became less important after adjusting for the effects of women's characteristics. Meanwhile, the control variables in the final model, such as age of the respondents, educational level, and wealth index, were significantly associated with the occurrence of pregnancy complications. For instance, the risk of complications during 


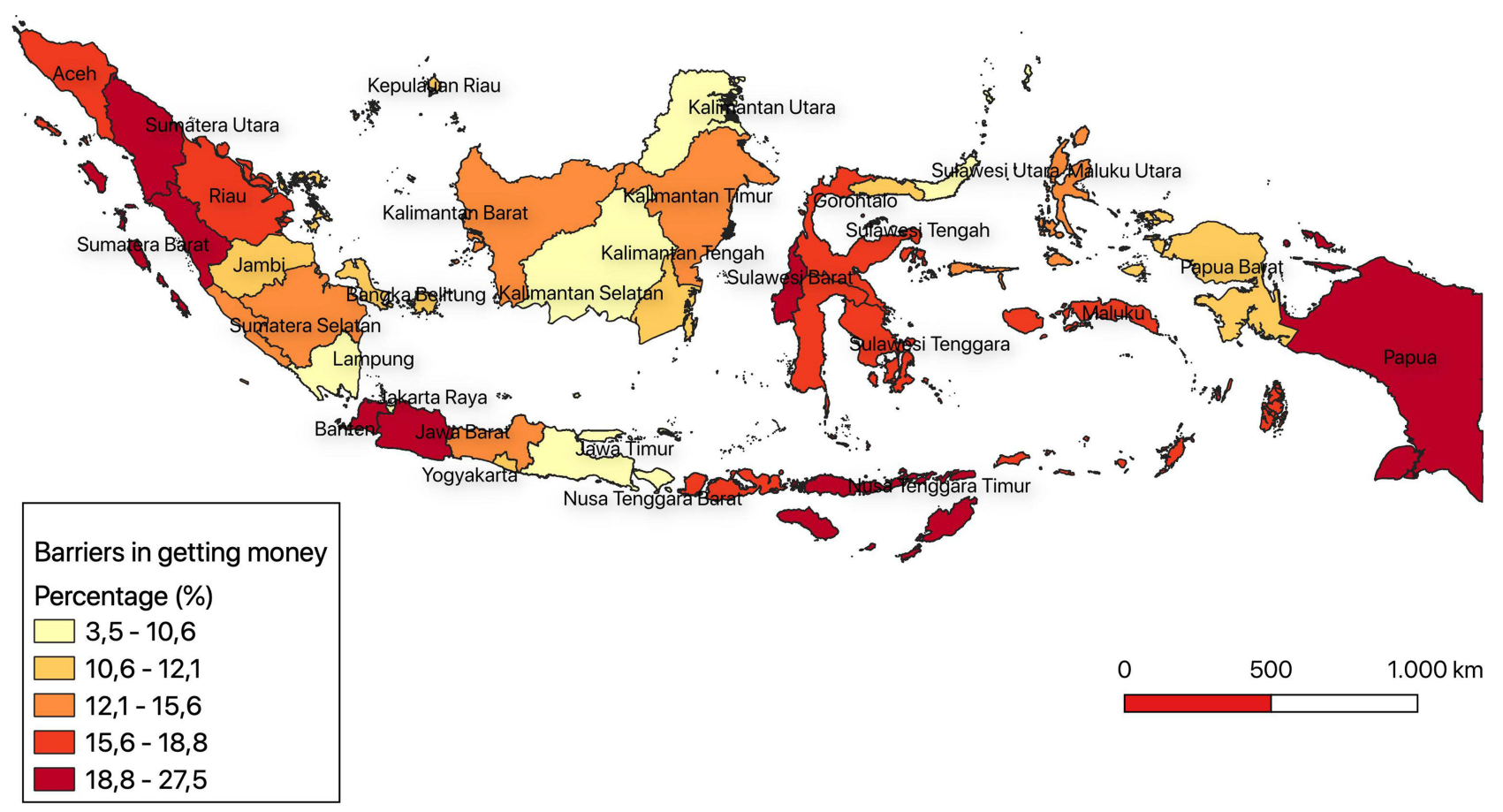

Figure 4 Distribution of barriers in getting money by province, IDHS 2017.

pregnancy was about two-fold higher for women from richer (OR: 1.49, 95\% CI: 1.24-1.80) and the richest households (OR: $1.38,95 \%$ CI: 1.12-1.70), compared to their counterparts from poor households.

When the results are stratified by population group, complications during pregnancy were more common among each group of women with barriers in urban areas. However, there were no differences in the likelihood of pregnancy complications between urban women who reported any type of barrier and those who did not have serious problems accessing health care (Supplementary Table 1). Women in rural areas who had problems in accessing healthcare services owing to financial burden, distance, and lack of a companion, were respectively $1.17,1.37$, and 1.19 times more likely to experience pregnancy complications. After adjusting for women's characteristics between urban and rural populations, the distance barrier had a significant association with pregnancy complications, for both urban (OR: 1.36, 95\% CI: 1.07-1.72) and rural women (OR: 1.52, 95\% CI: 1.24-1.87) (Supplementary Table 2).

\section{Discussion}

The findings of this study suggest that distance to health facility was the most significant predictor of pregnancy complications. Previous studies reported that physical distance to the health facility and lack of geographical access were reported as barriers to utilizing maternal healthcare services, including antenatal and obstetric care services. ${ }^{17-19}$ Inadequate utilization of ANC subsequently contributes to late detection of pregnancy complications. ${ }^{20}$

Indonesia is a geographically diverse country. Geographical disparities remain one of the main challenges for healthcare distribution and utilization in Indonesia. For instance, the proportion of ANC nonutilization was higher for women from the less developed regions, such as Maluku and Papua. ${ }^{21,22}$ This can be explained by the fact that most pregnant women in Maluku and Papua have extra costs associated with air and sea transportation for the women and their families, which are not covered by national health insurance or the JKN package. ${ }^{23}$ Also, Papua has a low number of physicians per population, although there has been an increase in the number of public health centers or puskesmas. ${ }^{24}$

In the present study, more women in Papua and other parts of the eastern and western regions had problems in accessing health care, as presented in Figures 1-4. Although not statistically significant, cultural and resource-related factors were common barriers encountered by the women. Figure 3 showed that the proportion of women in Aceh and North Sumatra reporting barriers in obtaining permission was the highest among the 34 provinces. These results are consistent with those of other 


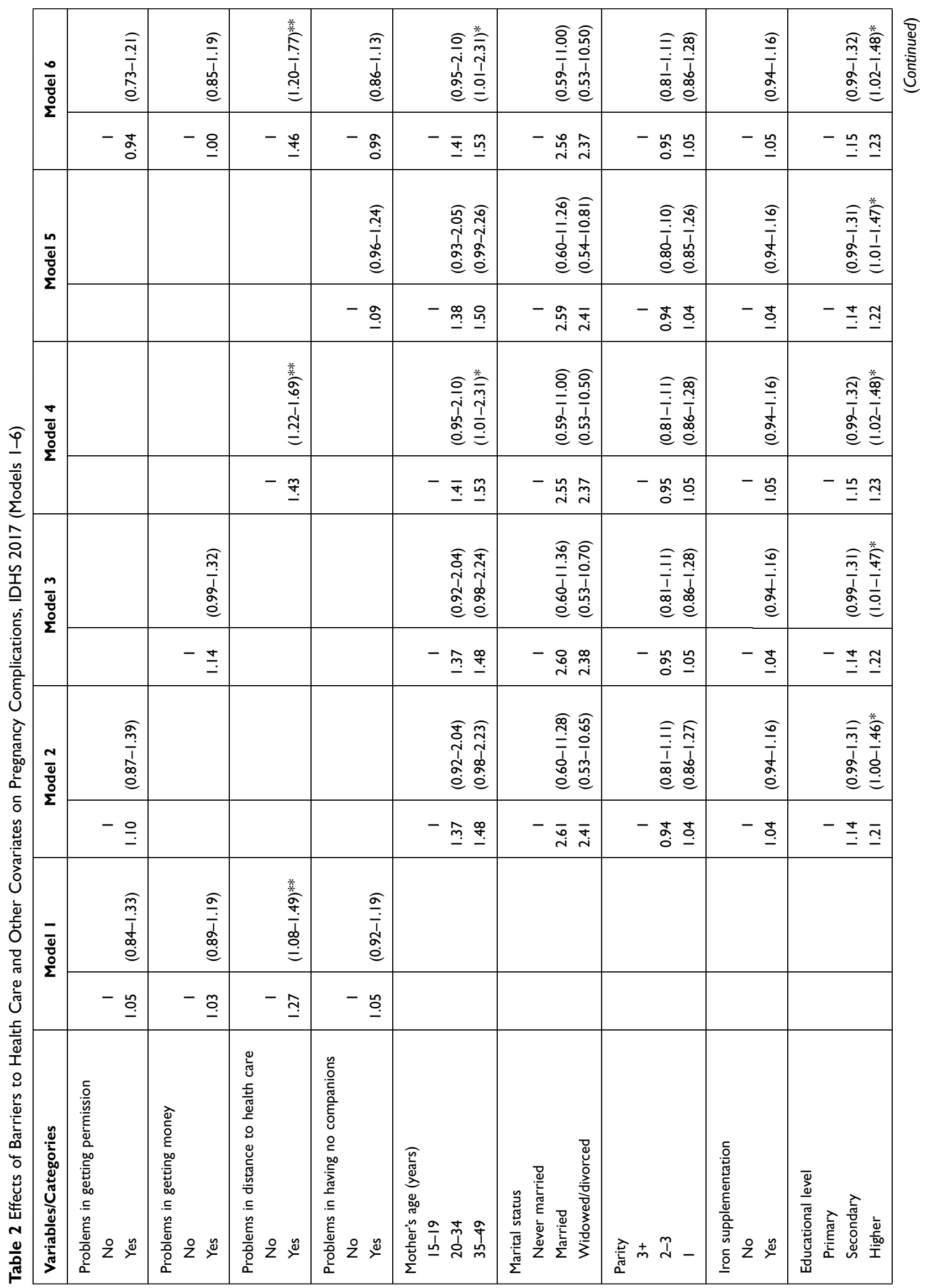




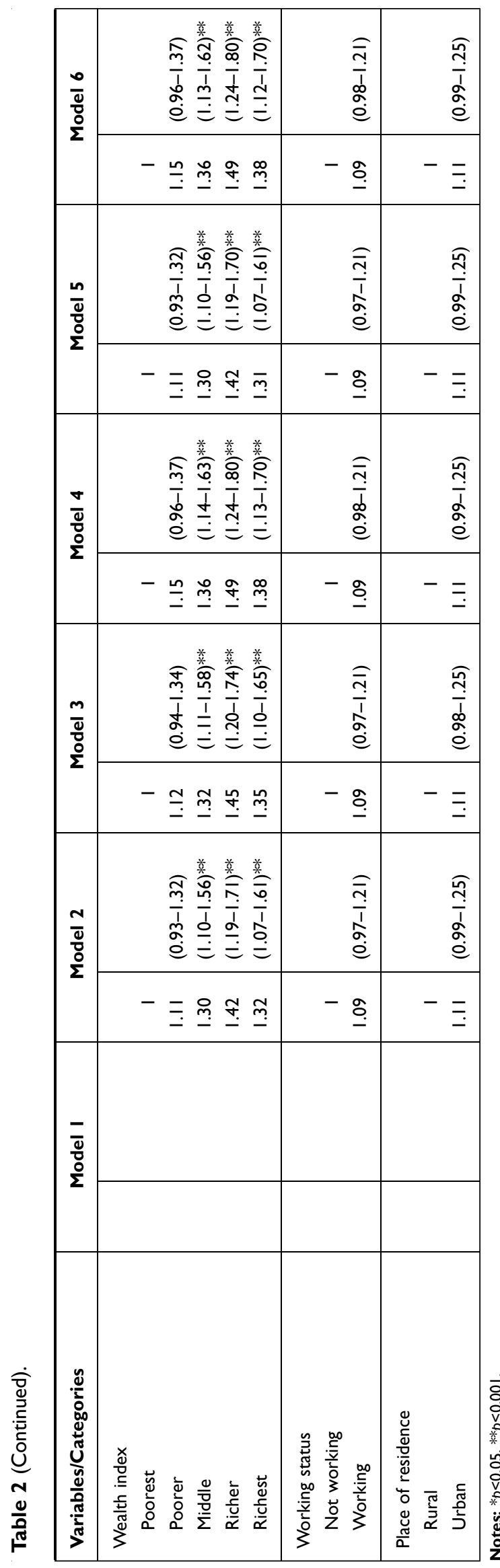

studies and suggest that the male involvement is important in increasing women's uptake of maternity care. ${ }^{25,26}$ The importance of social and cultural determinants of health in a community's health practices and outcomes has been reported in several studies. Thaddeus and Maine, in their paper "Too far to walk" in $1994,{ }^{27}$ defined three types of delay, in: 1) the decision to seek care; 2) reaching a health facility; and 3) receiving adequate and appropriate treatment, which can be conceptualized by the underlying sociocultural barriers in access to obstetric care. ${ }^{28}$ In addition, research suggests that the first delay is influenced by sociocultural factors, whereas the second delay is determined by economic and geographical factors. ${ }^{29}$

A qualitative study in Jayawijaya district, Papua, found that many women started their maternal care at home, with this care being performed either by family members or by community-based or health professionals, and never obtained care outside the home. ${ }^{30}$ A tendency for home treatment is mostly influenced by traditional practices, as women and their families tend to stay at this level regarding perceived health complications. Based on this careseeking pattern, the prominent barrier was cultural beliefs. However, an ethnographic study showed that delays in recognizing the severity of illness and seeking help could also trigger fatal conditions in women. This could be a result of the low level of participation by women in the decision to seek care. ${ }^{9}$ Similarly, during childbirth, a woman may not seek medical treatment until her husband grants permission for her to go to a health facility. ${ }^{31}$ This may happen because the husband is the main figure in the decision-making power relating to maternal health.

This study identified that distance to the health facility is the most prominent barrier which was significantly associated with pregnancy complications. Nevertheless, this study also found that women with high educational level and socioeconomic status (SES) reported more complications during pregnancy, regardless of the type of barriers reported. This finding seems to be inconsistent with other research, which found that women with lower SES received prenatal care less often and were at higher risk of obstetric complications. ${ }^{32}$ A possible explanation for this may be that women with high SES and educational status did not access maternal healthcare services unless they faced complications during their pregnancy. ${ }^{33}$ This rather contradictory result may be due to the lack of information on maternal diet and nutritional status, which were not analyzed in this study. A growing body of literature has investigated the contribution of maternal 
undernutrition and micronutrient deficiencies to maternal morbidity. ${ }^{34,35}$ One study found that a healthy dietary pattern during pregnancy was related to lower risks of gestational diabetes mellitus, gestational hypertension, and preeclampsia. ${ }^{32}$ These study results therefore need to be interpreted with caution.

The data reported in this study appear to support the assumptions that barriers related to socioeconomic status no longer put women at risk of having complications during pregnancy, although another study revealed that financial barriers can lead to delays in accessing health services. ${ }^{36}$ Opportunity costs and financial hardships related to being far from home were the underlying reasons for not using referral-level care. ${ }^{37}$ In Indonesia, the UHC scheme or JKN could be alleviating the financial burden of women accessing maternal health services in relation to medical costs. ${ }^{38}$ Since JKN was implemented, there has been a growth in ANC, facility-based deliveries, and the use of doctors to assist in the birth. Within a tiered health-service system, patients are required to undergo a basic examination in the primary health facility (a public health center, clinic, or private doctor's practice), and are referred to a secondary or tertiary care facility in the event of complications or any other emergency. ${ }^{13}$ This shift indicates that JKN is contributing toward improved access to skilled health professionals and quality delivery care.

However, there is some evidence to suggest that many women are still required to pay out-of-pocket expenses to access the services, ${ }^{39}$ including transportation costs. For most women in rural Indonesia, non-negligible transportation costs to access health are difficult to cover. ${ }^{40}$ The proportion of out-of-pocket spending for health in Indonesia was $40 \%$ in $2016 .^{41}$ Likewise, prolonged travel time and lack of adequate transportation remained significant barriers to accessing timely health care by rural communities in Malawi, although the provision of UHC has been implemented since 2004 through the Essential Health Package. ${ }^{42,43}$ Hence, geographical- and transportation-related obstacles, including long-distance travel, lack of a vehicle, and inadequate infrastructure, are still major discrepancies in healthcare access, which may increase the risk of women delaying access to timely and appropriate health care, and subsequently ending up facing severe obstetric complications.

Our findings suggested that bringing healthcare facilities physically closer to women could not only improve their access to the maternal health services, but also increase their opportunities to receive timely referrals to the emergency obstetric care services. Placing midwives close to the community is one strategy to ensure that pregnant women who experience complications in their pregnancy receive immediate help. The geographical and social proximity of a midwife to the women is a strength in facilitating integrated maternal health services. ${ }^{44}$

Essential interventions carried out by trained midwives, according to global standards and within a supportive environment, could prevent maternal and neonatal mortality by $40 \%$ and prevent stillbirths as much as $26 \%$ by $2035 .{ }^{45}$ A study in Kenya suggested that primary health facilities located in areas that are geographically isolated, difficult to reach, and with a lack of night transportation services, should be considered to be available outside operational hours, for example during weekends. This would anticipate that there are pregnant women who experience pregnancy complications or delivery outside these operational hours. ${ }^{46}$

In addition, pregnant women, especially those who live in remote or geographically isolated areas, are advised to plan their pregnancy visits and delivery, including the available mode of transportation, and record the details in the government-issued Maternal and Child Health Handbook (Buku Kesehatan Ibu Dan Anak). The content of this handbook includes birth preparedness and complication readiness, such as acknowledging the expected date of birth, deciding on a birth assistant and delivery place, saving money for delivery, preparing transportation to the delivery, and identifying potential blood donors. ${ }^{47}$ Local governments can also provide entitlement to reimbursement of transportation costs incurred by pregnant women through the national insurance scheme. ${ }^{48}$

Pregnant women and their families should be encouraged to obtain adequate knowledge about pregnancy complications and the benefits of having pregnancy checks in healthcare facilities. Despite financial barriers, knowledge and awareness of the importance and benefits of antenatal visits can act as a catalyst in meeting the minimum ANC criteria and ensuring the safety of pregnant women and their babies during pregnancy and delivery. ${ }^{46}$

Telehealth has also been developed as an alternative to cover healthcare in all regions in Indonesia. Since Indonesia is an archipelagic country with numerous islands, many populations in remote islands and areas would benefit from this geographical issue being addressed. $^{49}$ Moreover, telemedicine services support better knowledge among pregnant women, for example, the provision of telehealth education on the preparation for delivery. ${ }^{50}$ Finally, having a functioning referral system, with improved communication and organizational links 
between primary care, and frontline and referral hospitals, could potentially prevent women from experiencing delays in receiving timely and appropriate care, and subsequently lead to substantial improvements in pregnancy outcomes. $^{14}$ Active collaboration between referral levels and across sectors, as well as interregional integrated health facilities, may reduce the barriers to delivering maternal healthcare services. ${ }^{51}$

This study has several important limitations. The selection of variables was limited to the availability of the data collected, so this study did not analyze other kinds of barriers that may have influenced the occurrence of pregnancy complications. Another limitation is the information on distance, which may not necessarily reflect the remoteness of the healthcare facility. The degree to which distance is a barrier was not well described by the respondents. To accurately calculate the distance that the respondents had to travel would require a starting location for the journey and the estimated route taken to the health facility. ${ }^{52}$ The calculation may also include traffic congestion, which could have significantly increased the travel time.

\section{Conclusion}

This study showed that women who were perceived to have physical barriers to accessing care were more likely to have pregnancy complications; however, the association was not statistically significant for other barriers. A positive relationship between distance barriers and pregnancy complications confirms a need for future intervention programs and strategies at the district level that are tailored to the local context, especially in remote and resource-limited settings. The broader involvement of health sectors, local administration, and communities will help to tackle these barriers and thus provide support for decreasing all three delays (in seeking care, reaching a health facility, and receiving treatment) by ensuring better geographical access and the availability of emergency transport as part of local development. Further studies are also required to recognize problems and to establish an effective referral infrastructure in underresourced areas.

\section{Abbreviations}

ANC, antenatal care; UHC, universal health coverage; JKN, Jaminan Kesehatan Nasional; IDHS, Indonesia Demographic and Health Survey; OR, odds ratio; ICF, Inner-City Fund.

\section{Acknowledgment}

The authors wish to express gratitude to the National Family Planning Board for granting approval to use the data for this study.

\section{Disclosure}

The authors declare that there are no conflicts of interest in this work.

\section{References}

1. Ministry of Health Republic Indonesia. Situation of Mother Health (Situasi Kesehatan Ibu). Pusat Data Dan Informasi Kementerian Kesehatan RI. Jakarta: Ministry of Health; 2014:1-6.

2. World Health Organization. Managing Complications in Pregnancy and Childbirth: A Guide for Midwives and Doctors. 2nd. World Health Organization; 2017.

3. Rocha Filho EA, Costa ML, Cecatti JG, et al. Contribution of antepartum and intrapartum hemorrhage to the burden of maternal near miss and death in a national surveillance study. Acta Obstet Gynecol Scand. 2015;94(1):50-58. doi:10.1111/aogs.12529

4. Widyaningsih V. Increasing trends or sociodemographic changes? Decomposition analyses of maternal complication in Indonesia. KnE Life Sci. 2019;4:185-192. doi:10.18502/kls.v4i12.4173

5 . Widyaningsih V, Khotijah K. The patterns of self-reported maternal complications in Indonesia: are there rural-urban differences. Rural Remote Health. 2018;18:4609.

6. Bantas K, Aryastuti N, Gayatri D. The relationship between antenatal care with childbirth complication in Indonesian's mothers (data analysis of the Indonesia Demographic and Health Survey 2012). $J$ Epidemiol Kesehat Indones. 2019;2(2).

7. Ansariadi A, Manderson L. Antenatal care and women's birthing decisions in an Indonesian setting: does location matter? Rural Remote Health. 2015;15(2).

8. Tripathi V, Singh R. Regional differences in usage of antenatal care and safe delivery services in Indonesia: findings from a nationally representative survey. BMJ Open. 2017;7(2):e013408. doi:10.1136/ bmjopen-2016-013408

9. Belton S, Myers B, Ngana FR. Maternal deaths in eastern Indonesia: 20 years and still walking: an ethnographic study. BMC Pregnancy Childbirth. 2014;14:39. doi:10.1186/1471-2393-14-39

10. Pacagnella RC, Cecatti JG, Parpinelli MA, et al. Delays in receiving obstetric care and poor maternal outcomes: results from a national multicentre cross-sectional study. BMC Pregnancy Childbirth. 2014;14(1):159. doi:10.1186/1471-2393-14-159

11. Mahendradhata Y, Trisnantoro L, Listyadewi S, et al. The Republic of Indonesia Health System Review. India: WHO Regional Office for South-East Asia; 2017.

12. Agustina R, Dartanto T, Sitompul R, et al. Universal health coverage in Indonesia: concept, progress, and challenges. Lancet. 2019;393 (10166):75-102. doi:10.1016/S0140-6736(18)31647-7

13. Nugraheni WP, Mubasyiroh R, Hartono RK, Hotchkiss D. The influence of Jaminan Kesehatan Nasional (JKN) on the cost of delivery services in Indonesia. PLoS One. 2020;15(7):e0235176. doi:10.1371/ journal.pone. 0235176

14. Mahmood MA, Hendarto H, Laksana MAC, et al. Health system and quality of care factors contributing to maternal deaths in East Java, Indonesia. PLoS One. 2021;16(2):e0247911. doi:10.1371/journal. pone.0247911

15. National Population and Family Planning Board (BKKBN), Statistics Indonesia (BPS), Ministry of Health (Kemenkes), ICF. Indonesia Demographic and Health Survey 2017. Jakarta, Indonesia: National Population and Family Planning Board (BKKBN); 2018. 
16. StataCorp. Stata Statistical Software: Release 15 [Internet]. College Station, TX: StataCorp LLC; 2017.

17. Gabrysch S, Cousens S, Cox J, Campbell OMR, Bryce J. The influence of distance and level of care on delivery place in rural Zambia: a study of linked national data in a geographic information system. PLoS Med. 2011;8(1):e1000394. doi:10.1371/journal. pmed.1000394

18. Matsuoka S, Aiga H, Rasmey LC, Rathavy T, Okitsu A. Perceived barriers to utilization of maternal health services in rural Cambodia. Health Policy (New York). 2010;95(2-3):255-263. doi:10.1016/j. healthpol.2009.12.011

19. Kyei-Nimakoh M, Carolan-Olah M, McCann TV. Access barriers to obstetric care at health facilities in sub-Saharan Africa-a systematic review. Syst Rev. 2017;6(1):1-16. doi:10.1186/s13643017-0503-x

20. Nikiéma B, Beninguisse G, Haggerty JL. Providing information on pregnancy complications during antenatal visits: unmet educational needs in sub-Saharan Africa. Health Policy Plan. 2009;24 (5):367-376. doi:10.1093/heapol/czp017

21. Widyaningsih V, Khotijah B. Expanding the scope beyond mortality: burden and missed opportunities in maternal morbidity in Indonesia Glob Health Action. 2017;10(1):1339534. doi:10.1080/16549716. 2017.1339534

22. Laksono AD, Wulandari RD, Soedirham O. Regional disparities of health center utilization in rural Indonesia. Malaysian J Public Health Med. 2019;19(1):158-166.

23. Suparmi MIB, Lestari H Health insurance as a solution for barriers to maternal healthcare access in Indonesia. Jakarta. 2019.

24. Paramita SA, Yamazaki C, Setiawati EP, Koyama H. Distribution trends of Indonesia's health care resources in the decentralization era. Int J Health Plann Manage. 2018;33(2):e586-e596. doi:10.1002/ hpm. 2506

25. Rizkianti A, Afifah T, Saptarini I, Rakhmadi MF. Women's decisionmaking autonomy in the household and the use of maternal health services: an Indonesian case study. Midwifery. 2020;90:102816. doi:10.1016/j.midw.2020.102816

26. Susanti SS, Supradaniati SS, Diba F "Caring is Curing”: views from women in improving maternal health care in Aceh, Indonesia. In: Proceedings of the Aceh International Nursing Conference (AINC 2018). Banda Aceh: SCITEPRESS - Science and Technology Publications; 2020. 211-216.

27. Thaddeus S, Maine D. Too far to walk: maternal mortality in context. Soc Sci Med. 1994;38(8):1091-1110. doi:10.1016/0277-9536(94) 90226-7

28. Binder P, Johnsdotter S, Essén B. Conceptualising the prevention of adverse obstetric outcomes among immigrants using the "three delays" framework in a high-income context. Soc Sci Med. 2012;75 (11):2028-2036. doi:10.1016/j.socscimed.2012.08.010

29. Gabrysch S, Campbell OMR. Still too far to walk: literature review of the determinants of delivery service use. BMC Pregnancy Childbirth. 2009;9:34. doi:10.1186/1471-2393-9-34

30. Rosales A, Sulistyo S, Miko O, et al. Recognition of and care-seeking for maternal and newborn complications in Jayawijaya district, Papua province, Indonesia: a qualitative study. J Health Popul Nutr. 2017;36(S1):35-44. doi:10.1186/s41043-017-0122-0

31. Adedini SA, Odimegwu C, Bamiwuye O, Fadeyibi O, Wet N. Barriers to accessing health care in Nigeria: implications for child survival. Glob Health Action. 2014;7(1):23499. doi:10.3402/gha.v7.23499

32. Kim MK, Lee SM, Bae S-H, et al. Socioeconomic status can affect pregnancy outcomes and complications, even with a universal healthcare system. Int J Equity Health. 2018;17(1):2. doi:10.1186/s12939017-0715-7

33. Islam M, Sultana N. Risk factors for pregnancy related complications among urban slum and non-slum women in Bangladesh. BMC Pregnancy Childbirth. 2019;19(1):235. doi:10.1186/s12884-0192392-6
34. Todd CS, Chowdhury Z, Mahmud Z, et al. Maternal nutrition intervention and maternal complications in 4 districts of Bangladesh: a nested cross-sectional study. PLoS Med. 2019;16(10):e1002927. doi:10.1371/journal.pmed.1002927

35. Samur G, Akkus OO, Ede G, et al. Nutritional status among women with preeclampsia and healthy pregnant women. Prog Nutr. 2016;18 (4):360-368.

36. Echoka E, Makokha A, Dubourg D, Kombe Y, Nyandieka L, Byskov J. Barriers to emergency obstetric care services: accounts of survivors of life threatening obstetric complications in Malindi District, Kenya. Pan Afr Med J. 2014;17(Supp 1):4. doi:10.11694/ pamj.supp.2014.17.1.3042

37. Schalet AT. Beyond abstinence and risk: a new paradigm for adolescent sexual health. Womens Health Issues. 2011;21(3):S5-S7. doi:10.1016/j.whi.2011.01.007

38. Teplitskaya L, Dutta A. Has Indonesia's National Health Insurance Scheme Improved Access to Maternal and Newborn Health Services. Washington, DC: Health Policy Plus; 2018.

39. Smeru Research Institute. The Indonesia Universal Health Coverage (UHC): Initial Assessment of Challenges and Opportunities for Maternal and Child Health Care [Internet]. 2015.

40. Samarakoon S, Parinduri RA. The effects of social health insurance on women's healthcare use: evidence from Indonesia. Singapore Econ Rev. 2020;1-24. doi:10.1142/S0217590820500733

41. Chang AY, Cowling K, Micah AE; Global Burden of Disease Health Financing Collaborator Network. Past, present, and future of global health financing: a review of development assistance, government, out-of-pocket, and other private spending on health for 195 countries, 1995-2050. Lancet (London, England). 2019;393(10187):22 33-2260. doi:10.1016/S0140-6736(19)30841-4

42. Varela C, Young S, Mkandawire N, Groen RS, Banza L, Viste A. Transportation barriers to access health care for surgical conditions in Malawi: a cross sectional nationwide household survey. BMC Public Health. 2019;19(1):264. doi:10.1186/s12889-019-6577-8

43. Abiiro GA, Mbera GB, De Allegri M. Gaps in universal health coverage in Malawi: a qualitative study in rural communities. $B M C$ Health Serv Res. 2014;14(1):234. doi:10.1186/1472-6963-14-234

44. Michel-Schuldt M, McFadden A, Renfrew M, Homer C. The provision of midwife-led care in low-and middle-income countries: an integrative review. Midwifery. 2020;84:102659. doi:10.1016/j.midw.2020.102659

45. Nove A, Friberg IK, de Bernis L, et al. Potential impact of midwives in preventing and reducing maternal and neonatal mortality and stillbirths: a lives saved tool modelling study. Lancet Glob Health. 2021;9(1):e24-e32. doi:10.1016/S2214-109X(20)30397-1

46. Ochieng CA, Odhiambo AS. Barriers to formal health care seeking during pregnancy, childbirth and postnatal period: a qualitative study in Siaya County in rural Kenya. BMC Pregnancy Childbirth. 2019;19 (1):339. doi:10.1186/s12884-019-2485-2

47. Ministry of Health of Indonesia. Buku Kesehatan Ibu Dan Anak (Maternal and Child Health Handbook) [Internet]. Jakarta: Ministry of Health of Indonesia; 2020.

48. Dahab R, Sakellariou D. Barriers to accessing maternal care in low income countries in Africa: a systematic review. Int $J$ Environ Res Public Health. 2020;17(12):1-17. doi:10.3390/ijerph17124292

49. Djawad YA. The development of an intelligent e-health mobile application in Indonesia: a preliminary study. INSIST. 2019;4:240-245.

50. Arthyka Palifiana D, Khadijah S, Zakiyah Z. Edukasi telehealth pada ibu hamil sebagai upaya peningkatan pengetahuan tentang persiapan persalinan. Pros Semin Nas Has Penelit Dan Pengabdi Masy. 2020.

51. Murray SF, Pearson SC. Maternity referral systems in developing countries: current knowledge and future research needs. Soc Sci Med. 2006;62(9):2205-2215. doi:10.1016/j.socscimed.2005.10.025

52. Kelly C, Hulme C, Farragher T, Clarke G. Are differences in travel time or distance to healthcare for adults in global north countries associated with an impact on health outcomes? A systematic review. BMJ Open. 2016;6(11):e013059-e013059. doi:10.1136/bmjopen-2016-013059 


\section{Publish your work in this journal}

The International Journal of Women's Health is an international, peerreviewed open-access journal publishing original research, reports, editorials, reviews and commentaries on all aspects of women's healthcare including gynecology, obstetrics, and breast cancer. The

manuscript management system is completely online and includes a very quick and fair peer-review system, which is all easy to use. Visit http://www.dovepress.com/testimonials.php to read real quotes from published authors.

Submit your manuscript here: https://www.dovepress.com/international-journal-of-womens-health-journal 